\title{
Long-term visual traces of visually presented words*
}

\author{
DOUGLAS L. HINTZMAN \\ and \\ JEFFERY J. SUMMERS \\ University of Oregon, Eugene, Oreg. 97403
}

Long-term recognition memory was measured using test words that were either visually identical with or visually different from the original stimuli. Recognition latencies revealed an interaction consistent with the hypothesis that the visual memory code of a word persists, and can play a direct role in the recognition decision, for several minutes following presentation.

A skilled reader can transform information from one internal mode of representation to another-visual to phonemic to semantic-with little effort. Each type of internal representation, since it exists for some period of time, is a memory code; a question of interest to memory theorists, therefore, concerns how long each kind of code lasts.

The simplest assumption, and the one that was made implicitly by Wallach \& Averbach (1955), is that there are no appreciable differences in the rates of forgetting of different memory codes. More recently, however, there have been attempts to identify the visual code exclusively with the visual sensory store, the phonemic code with short-term memory, and the semantic code with long-term memory-a view that implies vastly different durations for the three types of memory code. A major difficulty with this notion is that it has been proposed seriously only with regard to memory for verbal materials. It seems unlikely that phonemic or semantic memory codes could play a very important role in memory for visual scenes, faces, or complex, unfamiliar shapes; yet such materials are retained over relatively long intervals (e.g., Cermak, 1971; Hochberg \& Galper, 1967; Shepard, 1967).

If we assume that a long-term visual memory code underlies performance in such tasks, then the previously described position regarding verbal memory appears paradoxical. Why should the visual code for a complex form last much longer than that for a visually presented word? There is nothing about the stimuli themselves that suggests an answer. Do the activities engaged in by the $S-$ the transformations to phonemic and semantic codes-destroy or replace the already existing visual code of the word? Or do transformations simply produce alternative codes of the word which co-exist in memory? If the latter is the case (cf. Posner \& Warren, 1972), then the role of each in retrieval may be determined more by

*The research reported herein was performed pursuant to a grant with the Office of Education, US Department of Health, Education, and Welfare. Contractors undertaking such projects under government sponsorship are encouraged to express freely their professional judgment in the conduct of the project. Points of view or opinions stated do not, therefore, necessarily represent official Office of Education position or policy. the nature of the task than by the length of the retention interval.

Recently, several investigators have concluded that, when verbal materials are preserted visually, the visual memory code persists and plays a role in retrieval for a minimum of several seconds (Parkinson, 1972; Scarborough, 1972; Warrington \& Shallice, 1972). Since the retention intervals are well beyond those attributed to the sensory store, these studies appear to support Murdock's (1967) hypothesis of modality-specific short-term memory stores.

The present study is concerned with even longer retention intervals, those usually assumed to involve only long-term memory. The question is whether, at intervals of this length, visually presented words are represented by a visual code (co-existing, presumably, with codes produced by subsequent transformations). Weak evidence that they may be comes from memory judgment experiments showing that information about the presentation modality of an individual word is retained for several minutes after presentation (Bray \& Batchelder, 1972; Hintzman, Block, \& Inskeep, 1972). The latter study also demonstrated some retention of intramodality distinctions (male vs female voice and uppercase block vs lowercase script letters). As pointed out by Hintzman et al (1972), the interpretation of these memory judgment results is equivocal, since the judgments could be based on abstract "semantic" tags. More critical to the question concerning visual representation in long-term memory was their finding that Ss tended to make fewer recognition errors when a word was presented for test in the style of type in which it had been presented originally than when the type style was changed. This small but statistically significant effect suggests that a visual code of the original stimulus was stored in long-term memory and that the physical dimensions of the code played a direct part in the recognition decision.

The purpose of the experiment reported here was to provide further evidence regarding the role of physical identity of presentation and test stimuli in long-term recognition memory for words. Computer-generated words were presented on a visual display, half in one mode (large uppercase letters) and half in another (small lowercase letters). A yes-no recognition test followed, in which all stimuli appeared in the same mode. Half of the Ss were tested using one mode and half were tested using the other. Recognition latencies were measured. If a "literal copy" of the original experience of seeing the word is present in long-term memory, then the physical dimensions of the test stimulus, in addition to its semantic and phonemic dimensions, should be involved directly in the recognition decision. Recognition should be faster when presentation and test modes are the same than when they are different. 
Table 1

Mean of Median Correct Reaction Times and Error Percentages (in Parentheses)

\begin{tabular}{ccccc}
\hline \multirow{2}{*}{$\begin{array}{c}\text { Test Mode } \\
\text { (Group) }\end{array}$} & \multicolumn{3}{c}{ Presentation Mode } & \\
\cline { 2 - 4 } & Capital & Small & New & Mean \\
\hline \multirow{2}{*}{ Capital } & 909 & 934 & 1063 & 992 \\
& $(22.7)$ & $(27.0)$ & $(21.2)$ & $(23.0)$ \\
Small & 855 & 828 & 939 & 890 \\
& $(27.0)$ & $(27.9)$ & $(17.1)$ & $(22.3)$ \\
Mean & 882 & 881 & 1001 & 941 \\
& $(24.8)$ & $(27.4)$ & $(19.2)$ & $(22.7)$ \\
\hline
\end{tabular}

\section{METHOD}

\section{Materials}

Experimental items were 200 four-letter nouns. They were presented individually on a computer-controlled Hewlett-Packard 1300A oscilloscope. The stimuli appeared in two forms which, in order to minimize similarity, differed both in the size of the letters and in the case of the letters. In the capital mode the letters were uppercase and the area occupied by each four-letter word was approximately $3 / 8 \times 23 / 4$ in. In the small mode the letters were lowercase and occupied an area of $3 / 16 \times 1-3 / 8$ in.

\section{Design and Procedure}

During the study phase, 100 of the words were presented, with the $S$ instructed to remember the words for a later test. Each word appeared for $3.5 \mathrm{sec}$, with a .5 -sec interstimulus interval. The form of presentation was determined randomly, so that half of the words appeared in one mode and half appeared in the other. Half of the Ss saw one order and half saw another in which presentation modes of all the words were reversed, so that capital words became small and vice versa.

Following the study phase, Ss were read instructions for the recognition test. They were asked to indicate, for each test word, either "old" or "new" by pressing one of two keys situated on the table in front of them. The "old" response was always made with the right index finger and the "new" response with the left. Ss were told to respond as quickly as possible, while maintaining a fair degree of accuracy. The recognition test involved all 200 words, 100 "old" and 100 "new." It began approximately 3 min after the end of the study phase. During the test, each item was displayed on the oscilloscope until S responded, and there was a 2 -sec interstimulus interval between $S$ 's response to one word and the onset of the next word.

To a given $S$, the test words were all presented in the same mode. To half of the Ss the test words appeared in the capital mode and to half they appeared in the small mode.

\section{Subjects}

The Ss were 52 paid volunteers. The data of two Ss were discarded because more than $40 \%$ of their recognition test responses were errors. The 50 remaining $\mathrm{Ss}$ were divided equally among the two test-mode conditions.

\section{RESULTS AND DISCUSSION}

For each $S$ the median correct reaction time was determined for each condition. Means of these medians are presented, along with error percentages, in Table 1. For both groups of Ss, "hits" on old words were faster than correct rejections of new words, $F(1,48)=21.5$, $\mathrm{p}<.001$. This difference is subject to confounding, since "yes" responses were always made with the right hand and "no" responses were made with the left. The faster right-hand responses involved some cost: Errors were more frequent on old words than on new ones, $F(1,48)=6.50$. Neither measure comparing old and new items interacted significantly with groups, $\mathrm{p}>.05$. Although test mode appears to have had an overall effect on reaction time, this (between-Ss) comparison was not significant, $F(1,48)=2.25, p>.05$. Like reaction times, error rates of the two groups did not differ significantly, $\mathrm{F}<1$.

Of primary interest are the effects of original presentation mode of old words. In terms of main effects, neither reaction time nor error rate was affected by this variable, $p>.05$. However, presentation mode and test mode interacted to determine reaction time, $F(1,48)=6.31, p<.025$. The direction of the difference was that predicted by the "literal copy" hypothesis: Ss in either group responded faster when the presentation and test modes were the same than when they were different. Although error rates tended to reflect an interaction in the same direction, the effect was not significant, $F(1,48)=1.89, p>.05$. Note that the Presentation by Test Mode interaction, unlike the difference between old and new items, cannot be attributed to speed-accuracy tradeoff, since both reaction times and error rates tended to be lower when presentation and test modes matched.

The interaction indicates that the effectiveness with which a recognition test word retrieves a trace of a past occurrence depends in part upon the physical similarity between the test word and the original stimulus. The visual dimensions of the test word would be expected to play such a role in the recognition decision only if a visual code of the original stimulus were still present at the time of the test. The important point is that the stored information not only provides a basis for judgments of input mode, as has been demonstrated in other studies, but also plays a direct role in retrieval. In Underwood's (1969) terms, the visual information is a "retrieval attribute" as well as a "discriminative attribute" of the memory trace.

The retention intervals in the present study were beyond the range not only of the visual sensory store but also of what is usually assumed to be that of short-term memory. The shortest possible retention interval-for an item that by chance happened to be both the last presented and the first tested-would have been approximately $3 \mathrm{~min}$. The average retention interval for all words was about $10 \frac{1}{2} \mathrm{~min}$. The visual code of a visually presented word thus appears to be longer lasting than many have assumed.

It may be hypothesized that the basic difference between the trace of a visually presented word and that of a nonverbal visual stimulus is not one of the durability of the visual memory code, but one of complexity. In the case of a word, there are phonemic and semantic codes that co-exist in storage with the visual code and obscure its presence, in many tasks, through the roles they play in retrieval. In order to track 
the forgetting of the visual code, of course, retention intervals must be varied systematically. Appropriate experiments, confirming the presented finding and extending it to the auditory modality, have been conducted by Kim Kirsner. ${ }^{1}$

\section{REFERENCES}

Bray, N. W., \& Batchelder, W. H. Effects of instructions and retention interval on memory of presentation mode. Journal of Verbal Learning \& Verbal Behavior, 1972, 11, 367-374.

Cermak, G. W. Short-term recognition memory for complex free-form figures. Psychonomic Science, 1971, 25, 209-211.

Hintzman, D. L., Block, R. A., \& Inskeep, N. R. Memory for mode of input. Journal of Verbal Learning \& Verbal Behavior, 1972, 11, 741-749.

Hochberg, J., \& Galper, R. E. Recognition of faces: I. An exploratory study. Psychonomic Science, 1967, 9, 619-620.

Murdock, B. B. Auditory and visual stores in short term memory. Acta Psychologica, 1967, 27, 316-324.

Parkinson, S. R. Short-term memory while shadowing: Multiple-item recall of visually and of aurally presented letters. Journal of Experimental Psychology, 1972, 92, 256-265.
Posner, M. I., \& Warren, R. E. Traces, concepts, and conscious constructions. In A. W. Melton and E. Martin (Eds.), Coding processes in human memory. Washington, D.C: Winston, 1972.

Scarborough, D. L. Stimulus modality effects on forgetting in short-term memory. Journal of Experimental Psychology, 1972, 95, 285-289.

Shepard, R. N. Recognition memory for words, sentences, and pictures. Journal of Verbal Learning \& Verbal Behavior, 1967, 6, 156-163.

Underwood, B. J. Attributes of memory. Psychological Review, $1969,76,559-573$.

Wallach, H., \& Averbach, E. On memory modalities. American Journal of Psychology, 1955, 68, 249-257.

Warrington, E. K., \& Shallice, T. Neuropsy chological evidence of visual storage in short-term memory tasks. Quarterly Jolinal of Experimental Psychology, 1972, 24, 30-40.

\section{NOTE}

1. Personal communication, August, 1972.

(Received for publication February 16, 1973.) 